\title{
The role of single odontoid screw fixation in treatment of odontoid fracture type II
}

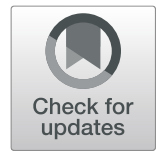

\author{
Ahmed Rizk Elkholy (D), Ashraf Mohamed Farid and Ebrahim Ahmed Shamhoot
}

\begin{abstract}
Background: Odontoid fractures are the most common cervical fractures specially type II. Anterior odontoid screw fixation has many advantages with low incidence of surgical complications.

Purpose: To evaluate the role of single odontoid screw fixation in surgical treatment of odontoid fracture type II. Study design: A retrospective clinical case series.

Patients and methods: Twelve patients with acute traumatic odontoid fracture type II were surgically treated by anterior single odontoid screw fixation. The visual analogue scale (VAS) and neck disability index (NDI) were used to evaluate the functional outcome among our patients. Plain radiography and CT cervical spine were done in all cases preoperatively and during our period of follow-up (6 months). Preoperative MRI cervical spine was done in all cases.
\end{abstract}

Results: The study included 12 patients, four of them (33.3\%) were females, and 8 (66.7\%) were males with a mean age of $41.7 \pm 11.4$ years. All patients had acute traumatic odontoid fracture type II, oblique fractures in 10 (83.3\%) cases, and transverse fractures in $2(16.7 \%)$ cases. All cases operated for anterior single odontoid screw fixation. During our period of follow-up, VAS and neck disability index were improved in all cases. There were 5 cases (41.7\%) with transient dysphagia. Solid fusion was achieved in all cases except in one patient (8.3\%) (fibrous union).

Conclusion: Single odontoid screw fixation is useful and safe procedure in surgical treatment of odontoid fractures type II. Careful attention to the technical aspects of the procedure and selection of patients are essential for good outcome.

Keywords: Odontoid screw fixation, Odontoid fractures type II

\section{Introduction}

Odontoid fractures are classified into three types according to the fracture site: Type I: the fracture line traverses the odontoid tip above the transverse ligament, type II: the fracture line traverses the odontoid base (the most common type), and type III: fracture includes the body of $\mathrm{C}_{2}$. Type I and III fractures are usually stable and do not need surgery but controversy remains about the ideal treatment for type II fracture [1].

External immobilization with a cervical collar or halo vest is usually used for non-surgical treatment of odontoid fractures type II with good healing rates from 37 to

\footnotetext{
*Correspondence: elkholyneurosurgery@yahoo.com

Neurosurgery Department, Faculty of Medicine, Tanta University, Tanta, Egypt
}

$75 \%$ but it is associated with mortality rates from 26 to $47 \%$ due to prolonged external immobilization which resulted in many respiratory related complications specially in elderly patients $[2,3]$.

Posterior $C_{1}-C_{2}$ fixation is the traditional method for surgical treatment of odontoid fractures with good fusion rates ranged from 92.8 to $100 \%$ [2]. It is, however, associated with high rates of morbidity and mortality and also resulted in decreased cervical motion specially axial rotation [4-6].

Nakanishi in [7] and Bohler in [8] introduced the anterior screw fixation for surgical treatment of odontoid fracture type II. This procedure achieves immediate stabilization, maintains rotation of $\mathrm{C}_{1}$ on $\mathrm{C}_{2}$, and it has

\section{Springer Open}

(๑) The Author(s). 2020 Open Access This article is licensed under a Creative Commons Attribution 4.0 International License, which permits use, sharing, adaptation, distribution and reproduction in any medium or format, as long as you give appropriate credit to the original author(s) and the source, provide a link to the Creative Commons licence, and indicate if changes were made. The images or other third party material in this article are included in the article's Creative Commons licence, unless indicated otherwise in a credit line to the material. If material is not included in the article's Creative Commons licence and your intended use is not permitted by statutory regulation or exceeds the permitted use, you will need to obtain permission directly from the copyright holder. To view a copy of this licence, visit http://creativecommons.org/licenses/by/4.0/. 
low incidence of complications with good fusion rates [9-11].

This is a retrospective clinical case series study to evaluate the role of single odontoid screw fixation in surgical treatment of odontoid fracture type II.

\section{Methods}

This study was conducted on 12 patients with acute traumatic odontoid fractures type II (Grauer type IIB) [12], included 10 patients (83.3\%) with oblique fractures extended from the antero-superior of dens to posteroinferior portion, and two patients $(16.7 \%)$ with transverse fractures. There were 8 (66.7\%) males and $4(33.3 \%)$ females with a male-to-female ratio of 2:1. the age ranged between 25 and 65 years with a mean age of $41.7 \pm 11.4$ years. The duration of symptoms ranged between 1 and 6 days with a mean duration of $3.08 \pm 2.02$ days. We excluded from this study patients with odontoid fracture which extended from the anteroinferior of dens to posterosuperior, atlanto-axial dislocation, rupture of the transverse ligament, fracture of $\mathrm{C}_{2}$ body, chronic odontoid fracture, and patients with short neck or Barrel chest.

All patients were surgically treated by single anterior odontoid screw fixation. Patients were admitted and operated upon in the Department of Neurosurgery, Tanta University Hospital during the period from August 2015 to February 2018.

All patient's data, diagnosis, and treatment outcomes are confidentially kept private, and patients are presented by specific codes. An approval from the research ethics committee of the Faculty of Medicine Tanta University [Reference Number 32805] was obtained on December 26, 2018. Patients' consents for participation and for publication were not applicable. Additionally, the coauthors had neither financial nor non-financial competing interest to report.

\section{Preoperative evaluation}

All patients were subjected to full clinical history and examination (general and neurological). Neck pain and functional state were evaluated by VAS [13] for pain and neck disability index [14]. All fractures were evaluated by plain radiography (lateral and open mouth views) and multi-slice CT scan of the cervical spine. In addition, MRI cervical spine was done for all patients.

\section{Surgical technique}

All patients underwent awake intubation. After induction of general anesthesia, the patients were positioned in supine position with cervical hyperextension. A radiolucent gauze roll was inserted in the mouth to obtain a good open mouth view during surgery. Two C-Arm fluoroscopes were adjusted and positioned around the patient, one for lateral view and the other for open mouth view.

A transverse skin incision was used at the level of C56-disc space on the right side. After wide subcutaneous dissection, platysma muscle was opened vertically, and we used blunt dissection to expose the ventral spine from lower border of $\mathrm{C}_{2}$ to $\mathrm{C}_{6}$. The longus-colli was dissected laterally of the midline at the level of $\mathrm{C}_{2-3}$ disc then the annulus was opened to identify the entry point for drilling at the under surface of the anterior lip of $\mathrm{C}_{2}$ (interior end plate). Under the fluoroscopic guidance, a Kirschner wire (K-wire) was inserted from the entry point in the midline to go through $\mathrm{C}_{2}$ body and the fracture site to reach the posterior tip of the odontoid.

Tapping was done by using cannulated tap inserted on top of the K-wire. Finally, we inserted a single cannulated lag screw $(3.5 \mathrm{~mm}$ or $4.5 \mathrm{~mm})$ diameter. The measurements were adjusted according to the size of dens on the preoperative images and the depth of drilling during surgery. We used the cannulated lag screw system of Egifix Medical Company, ARE.

After removal of the wire, the screw was tightened, and the wound was closed in the standard fashion. The patients were discharged within $72 \mathrm{~h}$, and hard collar was used for 4-6 weeks after surgery.

\section{Post-operative evaluation}

The visual analogue scale for pain (VAS) and neck disability Index were used to evaluate the functional outcome among our patients during 6 months after surgery.

Plain $\mathrm{x}$-ray cervical spine (lateral and open mouth views) and multi-slice CT were done in all patients within $72 \mathrm{~h}$ after surgery and every 2 months up to 6 months to evaluate screw position and fusion status. Bone fusion is considered successful if there is trabeculation across the fracture site in CT scan and anatomical alignment of the fracture fragment in plain $\mathrm{x}$-ray without gap in the fracture site [15]. The expected time for bone fusion ranges from 2 to 8 months with an average of 4.5 months [1].

\section{Statistical analysis}

Analysis was done using student t-test with IBM SPSS statistics for windows, Version 21 (IBM Corp, Armonk, NY).

\section{Results}

This study included 12 patients with acute traumatic odontoid fractures type II. Neck pain was the only presenting symptom in all cases $(100 \%)$. There were no neurological deficits among our patients. According to the VAS for neck pain, there were 3 cases (25\%) with score 10,4 cases $(33.3 \%)$ were in score 9,4 cases $(33.3 \%)$ 


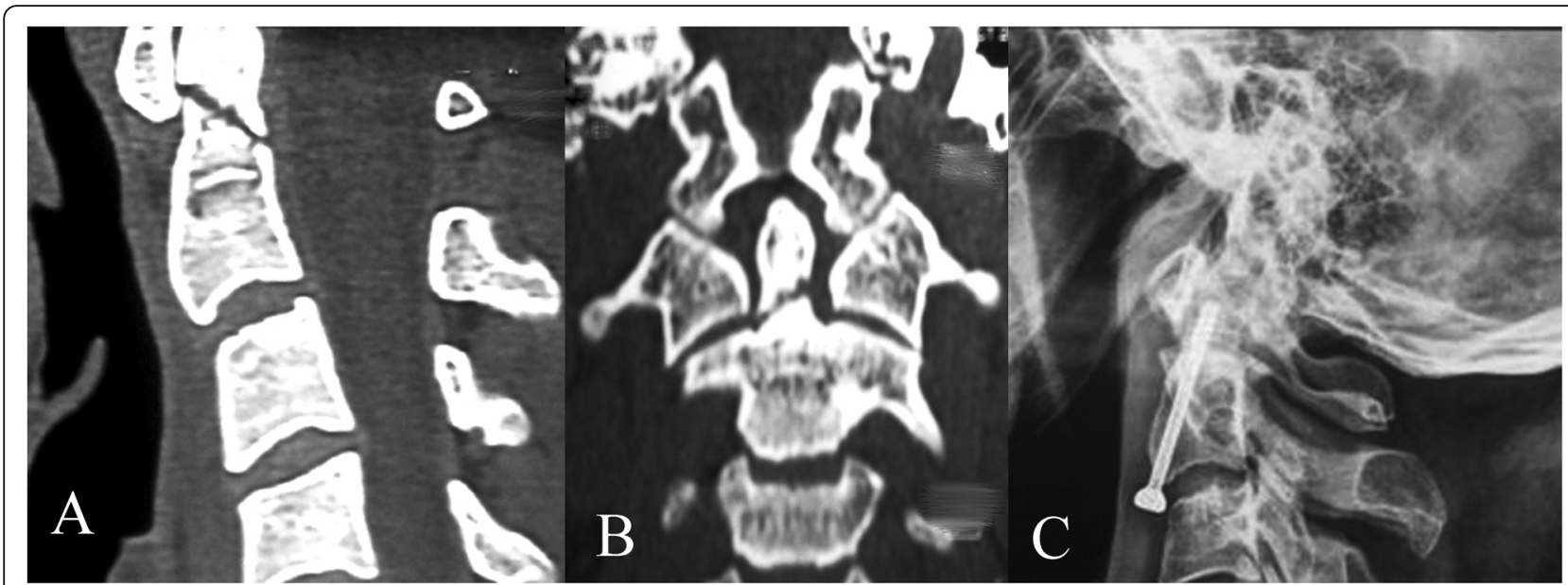

Fig. 1 a Preoperative sagittal CT cervical spine. b Preoperative coronal CT cervical spine. c Postoperative plain x-ray lateral view after 6 months

in score 8 , and one case $(8.3 \%)$ with score 7 . All patients $(100 \%)$ presented with severe neck pain.

Preoperative evaluation of patients according to neck disability score revealed no patient with scores 0-4 (no disability), scores 5-14 (mild disability), and even scores 15-24 (moderate disability). Patients with scores 25-34 (severe disability) were $5(41.7 \%)$ while patients with scores 35-50 (completely disabled) were 7 (58.3\%).

Preoperative radiological evaluation revealed odontoid fracture type II (Grauer type IIB) in all cases, oblique fracture (extending from antero-superior to posteroinferior) in 10 cases (83.3\%), and transverse fractures in $2(16.7 \%)$ cases. There was no case with atlanto-axial dislocation.

All patients were operated in supine position after awake intubation, and successful single odontoid screw insertion was achieved in all cases by the use of $2 \mathrm{C}$ Arms fluoroscopes without intra-operative complications. We did not use traction during surgery, but we used screw $3.5 \mathrm{~mm}$ diameter in 8 cases $(66.7 \%)$ and 4.5 $\mathrm{mm}$ diameter in 4 cases (33.3\%). Unicortical screw was inserted in all of the patients (Fig. 1).

The functional state of all patients improved after surgery and during the period of follow-up (6 months). The VAS for neck pain revealed $3(25 \%)$ cases with score 0,5 (41.7\%) cases with score 1, $3(25 \%)$ cases with score 2, and one case $(8.3 \%)$ of score 3 . Statistical analysis revealed that there was a significant improvement in scores of patients post-operatively compared to preoperative scores (Table 1$)(P=0.031,0.012,0.031,0.021$, 0.021 , and 0.031 , respectively).

The neck disability score revealed that 3 patients with scores $0-4$ (no disability) (25\%) and patients with scores 5-14 (mild disability) were $8(66.7 \%)$ patients and one patient (8.3\%) with scores 15-24 (moderate disability). There was no patient with scores 25-34 (severe disability) or scores 35-50 (complete disability). Statistical analysis revealed that there was a significant improvement in neck disability score in patients of the study post-operatively compared to preoperative scores (Table 2) ( $P=0.031,0.01,0.012$, and 0.01 , respectively).

During our period of follow-up, there were 5 cases (41.7\%) with transient dysphagia which resolved spontaneously within 1 month. Solid fusion was achieved in 11 patients $(91.7 \%)$, and we had one patient (65 years old) (8.3\%) with no solid fusion (fibrous union) in postoperative images but the fracture was stable radiologically, and the screw was intact and in place.

\section{Discussion}

Mazur et al. [16] reported different contraindications for odontoid screw fixation that included an oblique fracture line from anterior-inferior to postero-superior part of the dens, incompetent transverse ligament, chronic fractures, pathological fracture, and patients with short neck or a barrel chest. They concluded that anterior

Table 1 VAS score preoperative and post-operative in cases of the study.

\begin{tabular}{lllllll}
\hline \multirow{2}{*}{$\begin{array}{l}\text { VAS } \\
\text { score }\end{array}$} & \multicolumn{2}{l}{ Preoperative } & & \multicolumn{2}{l}{ Post-operative } & $P$ \\
\cline { 2 - 3 } & No & $\%$ & & No & $\%$ & \\
\hline 0 & 0 & 0 & & 3 & $25 \%$ & $0.031^{*}$ \\
1 & 0 & 0 & & 5 & $41.7 \%$ & $0.012^{*}$ \\
2 & 0 & 0 & & 3 & $25 \%$ & $0.031^{*}$ \\
3 & 0 & 0 & & 1 & $8.3 \%$ & 0.326 \\
7 & 1 & $8.3 \%$ & & 0 & $0 \%$ & 0.326 \\
8 & 4 & $33.3 \%$ & & 0 & $0 \%$ & $0.021^{*}$ \\
9 & 4 & $33.3 \%$ & & 0 & $0 \%$ & $0.021^{*}$ \\
10 & 3 & $25 \%$ & & 0 & $0 \%$ & $0.031^{*}$ \\
\hline
\end{tabular}

*Significant as $p \leq 0.05$ 
Table 2 Neck disability score pre- and post-operative in cases of the study

\begin{tabular}{llllllll}
\hline Neck disability score & \multicolumn{2}{l}{ Preoperative } & & \multicolumn{2}{l}{ Post-operative } & $P$ \\
\cline { 2 - 3 } & No & $\%$ & & No. & $\%$ & \\
\hline 0-4 (no disability) & 0 & 0 & & 3 & $25 \%$ & $0.031^{*}$ \\
5-14 (mild disability) & 0 & 0 & 8 & $66.7 \%$ & $0.01^{*}$ \\
15-24 (moderate disability) & 0 & 0 & & $8.3 \%$ & 0.326 \\
25-34 (severe disability) & 5 & $41.7 \%$ & 0 & 0 & $0.012^{*}$ \\
35-50 (completely disabled) & 7 & $58.3 \%$ & 0 & 0 & $0.01^{*}$ \\
\hline
\end{tabular}

*Significant as $p \leq 0.05$

odontoid screw fixation is a technically challenging procedure, and patient's selection is essential for good outcome.

Our study included 12 patients with acute traumatic odontoid fracture type II: ten of them with oblique fractures extended from the antero-superior to the posteroinferior portion of dens and 2 patients with transverse fractures. We excluded from this study patients with oblique fractures extended from anterior-inferior to postero-superior part of dens, ruptured transverse ligament, chronic fractures, and patients with short neck. All patients had significant improvement in the VAS for neck pain and neck disability index after surgery and during our period of follow-up (6 months).

Meticulous surgical technique, perioperative patient position, identification of screw entry point, and proper insertion and use of K-wire with cannulated screw system are important keys for successful surgery without operative complications [16].

In this work, we used awake intubation, and patients were positioned supine with hyperextended neck. A gauze roll was inserted in the mouth to give good open mouth view during surgery. Two C-Arm fluoroscopes were used to obtain intraoperative lateral and anteroposterior views. Multiple images were taken to adjust the entry point, K-wire trajectory, and screw position. We used the cannulated screw system which inserted after adjustment of the K-wire position. All patients had successful surgery without intraoperative complications, and we had only 5 cases $(41.7 \%)$ of transient dysphagia after surgery which resolved in 1 month.

The use of 2 screws for odontoid fixation is technically difficult and require at least $9 \mathrm{~mm}$ of space for adequate placement [17]. The odontoid diameter in many cases not large enough to accommodate 2 screws and insertion of 2 screws reduces the available surface area for bone fusion [18, 19]. There is no biomechanical difference between the use of single or two screws for anterior odontoid fixation, and also both techniques have the same fusion rates $[2,20]$.

The study by Dalvandi et al. [21] included 37 patients in 5 years, and the study by fan et al. [22] was conducted on 24 patients in 8 years, both studies evaluated the results of single odontoid screw fixation in type II odontoid fractures, and they reported that it is safe and effective technique with high fusion rate.

In our study which included twelve patients in 2.5 years, we found the use of single odontoid screw is simple, safe procedure, and associated with good functional outcome and high fusion rate.

Bicortical anterior odontoid screw fixation increases the interfragmentary compression, but it is associated with increased incidence of screw migration beyond the apex and the high risk of neural or vascular injury [16], so that unicortical fixation by cannulated lag screw is recommended by some authors [23, 24].

In this study, we recommended the use of unicortical fixation by cannulated lag screw in all cases without any intra-operative complications. Solid fusion was achieved in all cases except one patient (8.3\%) as the serrations of the screw was partly involved in the fracture site so that the screw could not achieve its proper lag effect. This patient was stable radiologically during our period of follow-up (fibrous union).

In 2005, Grauer and his colleagues [12] classified odontoid fracture type II into three subtypes, and they found that the best treatment for odontoid fracture type IIB was anterior odontoid screw fixation. It was the same

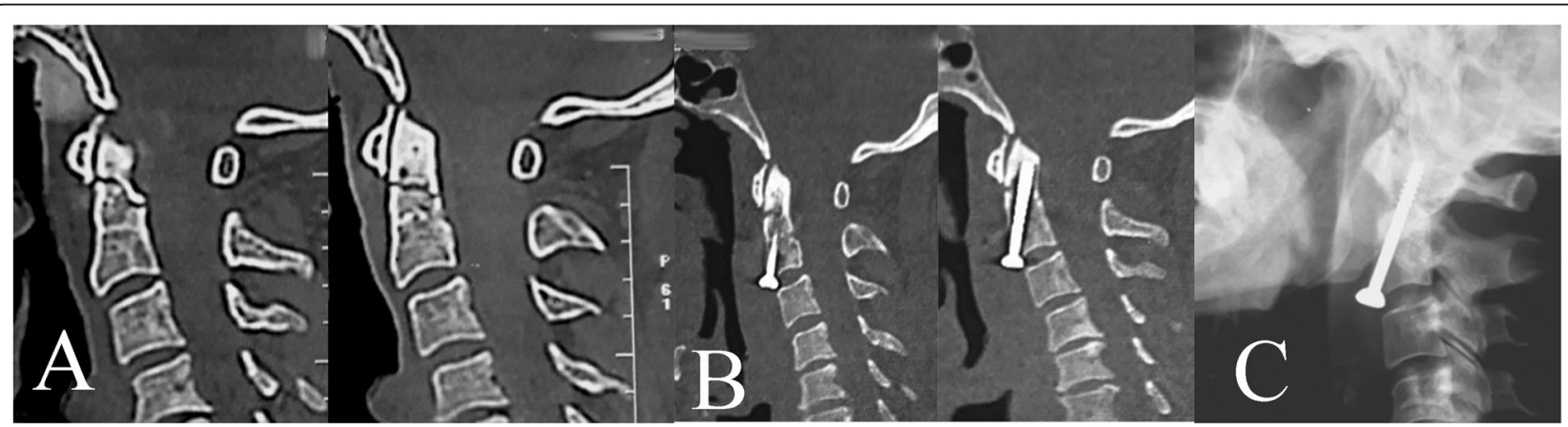

Fig. 2 a Preoperative sagittal $\subset T$ cervical spine. b Post-operative sagittal CT cervical spine after 2 months. c Post-operative plain x-ray after 6 months 
to our work as we successfully used anterior odontoid screw fixation in surgical treatment of our twelve patients with Grauer Type IIB fractures, and we had good clinical and radiological outcomes.

In our study, we agree with the results of Henry et al. [25], as they reported that anterior odontoid screw fixation is practical and valid option in treatment of odontoid fracture with fusion rate $92 \%$, and it was nearly the same rate for us $(91.7 \%)$ and also, they considered this procedure better than external immobilization and posterior fixation but in selected patients (Fig. 2).

The limitations of this study were being retrospective, limited number of patient,s and short follow-up period.

\section{Conclusion}

Single odontoid screw fixation is safe and effective method for surgical treatment of odontoid fracture type II (Grauer type II B). It is associated with high fusion rates and low incidence of complications. Careful attention to the technical aspect of the procedure and patient selection are the main keys for successful surgery and good outcome.

\section{Abbreviations}

ARE: Arab Republic of Egypt; CT: Computerized tomography; MRI: Magnetic resonance imaging; NDI: Neck disability index; VAS: The visual analogue scale

\section{Acknowledgements}

The authors sincerely thank El-Mahalawy M and all of the department members of Neurosurgery, Tanta University Hospital for their help in doing this work.

\section{Authors' contributions}

All authors equally participate in operating patients, data collection, data analysis, and scientific writing. All authors read and approved the final manuscript.

\section{Funding}

There was no funding for this study.

\section{Availability of data and materials}

The datasets used and/or analyzed during the current study are available from the corresponding author on reasonable request.

\section{Ethics approval and consent to participate}

The ethics committee, faculty of medicine, Tanta University was notified about the purpose of the study, patient evaluation, and safety of the surgical technique. The consent to participate was not applicable as it was a retrospective study. This study was granted by the research ethics committee, Faculty of Medicine, Tanta University (Approval code: 32806/12/ 18) obtained on December 2018.

\section{Consent for publication}

Not applicable as it is a retrospective study. We confirm that no personal data are incorporated in the study.

\section{Competing interests}

The authors declare that they have no competing interests.
Received: 12 March 2019 Accepted: 9 June 2020

Published online: 19 June 2020

\section{References}

1. Anderson LD, D'alonzo RT. Fractures of the odontoid process of the axis. J Bone Joint Surg [Am]. 1974;56(8):1663-74.

2. Apfelbaum EL, Lonsser RR, Veres R, Casey A. Direct anterior screw fixation of recent and remote odontoid fractures. J Neurosurg. 2000;93:227-36.

3. Denaro V, Papalia R, Dimartino A, Maffuli N. The best surgical treatment of type II fractures of the dens is still controversial. Clin Orthop Relat Res. 2011; 469:742-50.

4. Fielding JW, Hawkins RJ, Ratzan SA. Spine fusion for atlanto-axial instability. J Bone Joint Surg [Am]. 1976;58A:400-7.

5. Mestdagh H, Vigier P, Berger M, Urvoy P. Results of atlanto-axial arthrodesis with posterior cerclage for fractures of the odontoid process: a propos of 59 cases. Ann Chir. 1988:42:492-500.

6. Smith MD, Phillips WA, Hensinger RN. Complications of fusion to the upper cervical spine. Spine. 1991;16:702-5.

7. Nakanishi T. Internal fixation of the odontoid fracture. Cent Jpn J Orthop Trauma Surg. 1980;23:399-406.

8. Bohler J. Anterior stabilization for acute fractures and non-unions of dens. J Bone Joint Surg [Am]. 1982:64:18-27.

9. Geisler FH, Cheng C, Poka A, Brumback RJ. Anterior screw fixation of posteriorly displaced type II odontoid fractures. Neurosurgery. 1989;25(1): 30-87.

10. Montesano PX, Anderson PA, Schlehr F, Thalgott JS, Lowrey G. Odontoid fractures treated by anterior odontoid screw fixation. Spine. 1991;16(3 suppl):S33-7.

11. Montesano PX, Juach EC, Anderson PA, Benson DR, Hanson PB. Biomechanics of cervical spine internal fixation. Spine. 1991;16(3 suppl):S10-6.

12. Grauer JN, Shafi B, Hilibrand AS, Harrop JS, Kwon BK, Beiner JM, et al. Proposal of a modified, treatment-oriented classification of odontoid fractures. Spine J. 2005:5:123-9.

13. Wewers ME, Lowe NK. A critical review of visual analogue scales in the measurement of clinical phenomena. Res Nurs Health. 1990;13(4):227-36.

14. Vernon $\mathrm{H}$, Mior $\mathrm{S}$. The neck disability index: a study of reliability and validity. J Manip Phys Ther. 1991;14(7):409.

15. Daily AT, Hart D, Finn MA, Schmidt MH, Apfelbaum RI. Anterior fixation of odontoid fractures in an elderly population. J Neurosurg Spine. 2010;12(1):1-8.

16. Mazur MD, Mumert ML, Bisson EF, Schmidt MH. Avoiding pitfalls in anterior screw fixation for type II odontoid fractures. Neurosurg Focus. 2011;34:E7.

17. Nucci RC, Seigal S, Merola AA, Group J, Mroczek KJ, Dryer J, et al. Computed tomographic evaluation of the normal adult odontoid: implication of internal fixation. Spine (Phila Pa 1976). 1995;20:264-70.

18. Amling $M$, Hahn M, Wening VJ, Grote HJ, DElling G. The microarchitecture of the axis as a predisposing factor for fracture of the base of the odontoid process. A histromophometric analysis of twenty-two autopsy specimens. J Bone Joint Surg [Am]. 1994:76:1840-6.

19. Schaffler MB, Alson MD, Heller JG, Garfin SR. Morphology of the dens: a quantitative study. Spine (Phila Pa 1976). 1992;17:737-43.

20. Jenkins JD, Coric D, Branch CLJR. A clinical comparison of one and twoscrew odontoid fixation. J Neurosurg. 1998;89:366-70.

21. Dalvandi M, Mohamadi AR, Ahmadi SA. Anterior single Lag screw fixation in type II odontoid process fractures: a case series with literature review. J Iran Clin Res. 2015;1(2):62-6.

22. Fan KF, Liao JC, Niu CC, Chen LH, Chen WJ, Lee MS. Anterior single-screw fixation in 24 patients with Type II odontoid fractures, Technical Note. Formosan Journal of Musculoskeletal Disorders. 2013;4:26-31.

23. Eap C, Barresi L, Ohl X, Saddiki R, Mensa C, Madi K, et al. Odontoid fractures anterior screw fxation: a continuous series of 36 cases. Orthop Traumatol Surg Res. 2010;96:748-52.

24. Magee W, Hettwer W, Badra M, Bay B, Hart R. Biomechanical comparison of a fully threaded, variable pitch screw and a partially threaded lag screw for internal fxation of Type II dens fractures. Spine (Phila Pa 1976). 2007;32: E475-9.

25. Henry AD, Bohly J, Grosse A. Fixation of odontoid fractures by an anterior screw. J Bone Joint Surg [Br]. 1999;81-B:472-7.

\section{Publisher's Note}

Springer Nature remains neutral with regard to jurisdictional claims in published maps and institutional affiliations. 